\title{
A LUTA POR RECONHECIMENTO DA MULHER-PESQUISADORA NA FILOSOFIA E NA CIÊNCIA: EXPERIÊNCIAS DE MULHERES NORDESTINAS NA UNIVERSIDADE PÚBLICA
}

\author{
THE STRUGGLE FOR THE RECOGNITION OF WOMEN- \\ RESEARCHERS IN PHILOSOPHY AND SCIENCE: EXPERIENCES OF \\ NORTHEASTERN WOMEN AT THE PUBLIC UNIVERSITY
}

\author{
Santana Taciana Mariz Félix ${ }^{1}$ \\ Maria Reilta Dantas Cirino ${ }^{2}$ \\ Shirlene Santos Mafra Medeiros ${ }^{3}$
}

Recebido em: 07/2020

Aprovado em: 09/2020

\begin{abstract}
Resumo: O desenvolvimento filosófico, científico e acadêmico, reservou um lugar predominante ao sujeito masculino europeu aristocrata. Constituindo, produções de conhecimentos androcêntricos baseados em um conceito de suposta objetividade e neutralidade entre sujeito e objeto de investigação. Nessa perspectiva, o presente artigo objetiva retratar alguns dos percalços da trajetória das mulheres na filosofia, na ciência e na academia enquanto pensadora, produtora de conhecimento, educadora e educanda nos contextos universitários, os quais se constituem, a partir da realidade aqui ressaltada, em expressões cotidianas de resistências nos espaços públicos. Nos propomos, através do relato reflexivo de nossa trajetória de vidas entrelaçadas à pesquisa bibliográfica e consulta documental, a pensar sobre o lugar ocupado pela mulher-pesquisadora na universidade brasileira, tomando como cenário, especificamente, a Universidade do Estado do Rio Grande do Norte UERN, Campus Caicó, onde exercemos nossas atividades enquanto mulheres, respectivamente, docentes-pesquisadoras e de discente-pesquisadora no Curso de Licenciatura em Filosofia. Ao final foi possível identificar que existe uma tendência de inserção nacional da mulher nas Instituições de Ensino Superior, contudo, ainda revelam-se, na realidade pesquisada, formas sutis de silenciamento. Tais aspectos necessitam ser bem problematizados, pois os mecanismos de segregação das ações das mulheres passam por gestos mínimos e intersecções de realidades cotidianamente implícitas nas
\end{abstract}

\footnotetext{
${ }^{1}$ Discente no Curso de Licenciatura em Filosofia, Universidade do Estado do Rio Grande do Norte (UERN), Campus Avançado de Caicó (CaC), e-mail: tacianamariz123@gmail.com. Lattes: http://lattes.cnpq.br/7358597785549754.

${ }^{2}$ Professora Adjunta IV, da Universidade do Estado do Rio Grande do Norte - UERN, Curso de Licenciatura em Filosofia e do Mestrado Profissional em Ensino de Filosofia - PROF- FILO (Polo Caicó-UERN). Doutora em Educação (PROPED/UERJ). Líder do Grupo de Pesquisa Ensinar e Aprender na Educação Básica - GPEAEB/UERN. E-mail: mariareilta@ hotmail.com. Lattes: http://lattes.cnpq.br/5734550223711436.

${ }^{3}$ Professora Adjunta IV, da Universidade do Estado do Rio Grande do Norte - UERN, Curso de Licenciatura em Filosofia e do Mestrado Profissional em Ensino de Filosofia - PROF- FILO (Polo Caicó-UERN). Doutora em Educação (PPGMLS/UESB). Líder do Grupo de Pesquisa Educação, Saúde e Pensamento Complexo. E-mail: shirlenemafra@yahoo.com.br. Lattes: http://lattes.cnpq.br/4651108343068735.
} 
relações sociais internas e externas que se estabelecem entre homens e mulheres produzindo e silenciando processos de subjetivação que exigem um estado de atenção permanente, de resistência e resiliência para superação das situações adversas tão pertinentes aos povos nordestinos e para que o lugar ocupado pelas mulheres-docentes-discentes-pesquisadoras não continue a ser negado de maneira velada.

Palavras-chave: Androcentrismo; Gênero; Mulher-pesquisadora; Filosofia; Universidade Pública.

\begin{abstract}
The philosophical, scientific and academic development, has reserved a predominant place for the aristocratic European male subject. Constituting, androcentric knowledge production based on a concept of supposed objectivity and neutrality between subject and object of investigation. In this perspective, this article aims to portray some of the obstacles in the trajectory of women in philosophy, science and academia as a thinker, knowledge producer, educator and student in university contexts, which are constituted, based on the reality highlighted here, in everyday expressions of resistance in public spaces. We propose, through the reflective account of our trajectory of lives intertwined with bibliographic research and documentary consultation, to think about the place occupied by the woman-researcher at the Brazilian university, taking as a scenario, specifically, the State University of Rio Grande do Norte - UERN, Campus Caicó, where we exercise our activities as women, respectively, teacher-researchers and student-researcher in the Philosophy Degree Course. In the end, it was possible to identify that there is a tendency for national insertion of women in Higher Education Institutions, however, still revealed, in the researched reality, subtle forms of silencing. Such aspects need to be well problematized, as the mechanisms of segregation of women's actions go through minimal gestures and intersections of realities that are daily implicit in the internal and external social relations that are established between men and women, producing and silencing subjectification processes that require a state of permanent attention, resistance and resilience to overcome adverse situations that are so pertinent to the Northeastern peoples and that the place occupied by women-teachers-students-researchers does not continue to be denied in a veiled way.
\end{abstract}

Keywords: Androcentrism; Genre; Researcher woman; Philosophy; Public university.

\title{
Introdução
}

Esse texto objetiva retratar alguns dos percalços da trajetória das mulheres na filosofia, na ciência e na academia enquanto pensadora, produtora de conhecimento, educadora e educanda que ocuparam e ocupam espaços de conhecimentos atribuídos ao domínio masculinoeuropeu, de modo que abordaremos alguns dos atuais contextos universitários, os quais se constituem, a partir da realidade aqui ressaltada, em expressões cotidianas de resistências nos espaços de produções de filosóficas e científicas.

Trago à tona para provocar, metaforicamente, a poesia de uma notória mulher-potiguar, Marize Castro, que retrata em sua obra Poço, festim, mosaico o que acontece a uma mulher quando consegue abrir brechas dentro do contexto dos sistemas de opressão: “[...] elas viram pássaros porque do alto têm a certeza que serão salvas e de lá contemplam o mundo. escrevem livros. constroem casas. parques. elipses. [...]. dão aula. vão para o palco.[...]. e se tornam metáforas. anáforas. foguetes.” 
Na perspectiva poética de abrir brechas nos propomos pensar o lugar ocupado pela mulher filósofa e pesquisadora na universidade pública brasileira, tomando como cenário a Universidade do Estado do Rio Grande do Norte - UERN, Campus Caicó, o qual é locus de nossas atividades enquanto mulheres, respectivamente, docente-pesquisadora, desde o ano de 2004/2005 e de discente-pesquisadora, desde 2018 no curso de Licenciatura em Filosofia.

Atualmente, encontram-se resquícios de um desenvolvimento filosófico e científico que reservou historicamente um papel predominante ao gênero masculino de classe dominante. De modo que, se constituiu produções de conhecimentos e noções de realidades androcêntricas ${ }^{4}$, tomando as experiências masculinas europeias como universais, baseadas em um conceito de suposta objetividade e neutralidade entre sujeito e objeto de investigação. Essa postura na filosofia e na ciência evoca e associa-se ao modelo hegemônico europeu-masculino-cultural que atribui ao homem as características de força, razão, determinação e distanciamento das ações, concomitantemente, distanciava-se do equivocado conceito de determinismo biológico ${ }^{5}$, de incapacidade racional atribuídas ao gênero feminino, entendendo esse com características dóceis e maternais, pela construção de ideal da mulher branca bem-nascida.

Como identifica Cyrulnik (2004, p. 205, ) de que justifica-se na hierarquia o lugar social ocupado por cada Ser como sendo de natureza natural: "Cada um ocupava o lugar que lhe era atribuído, por ordem imutável: as mulheres por seu ventre, os homens por seus braços e os aristopadres por suas palavras.” Nessa perspectiva, diz Mead (2010, p. 61) nas “[...] interações sociais, a partir da linguagem e das experiências" as mulheres foram excluídas dos espaços públicos e acadêmicos, tornando a mulher um Outro, como coloca Simone de Beauvoir (2009, p. 19), que a mulher não é definida em si mesma, mas a partir de experiências e perspectivas masculinas, sendo o homem o Sujeito Absoluto e ela, a mulher o Outro ${ }^{6}$, assim como "Os judeus são 'outros' para o antissemita, os negros para os racistas norte-americanos, os indígenas para os colonos, os proletários para as classes dos proprietários", assim para o homem se afirmar como sujeito essencial, e torna a mulher no Outro, no objeto.

Tomaremos como fundamentos teóricos os estudos de Lugones (2014), Schienbinger (2001), Beauvoir (2009), Pacheco (2015), Mead (2010). E assim, observamos que até os anos

\footnotetext{
4 O androcentrismo é a (comumente não contada) visão de que o homem é o ponto de referência para o que é normal para seres humanos. A palavra [androcentrismo], que significa literalmente "os homens no centro". (LINDEMANN, 2006).

${ }^{5}$ A identidade na perspectiva meadiana, segundo Medeiros $(2015$, p. 56$)$ é um construto social. "O corpo, como tal, não é um self. Torna-se um self somente quando é desenvolvida a mente, no contexto da experiência social”.

${ }^{6}$ Simone cunha a categoria de "Outro" baseada na dialética do senhor e do escravo de Hegel.
} 
1800, a mulher branca (mesmo burguesa) não tinha acesso legal ao Ensino Superior. No Brasil, apenas em 1940 tivemos a primeira mulher negra na Universidade, percebemos aqui os abismos coloniais entre classe, raça e localização geográfica. Atualmente, o Censo da Educação Superior de 2016 apontou que as mulheres representavam 57,2\% dos estudantes matriculados em cursos de graduação (FERNANDES, 2019). Mas, se é fato que, nós mulheres, temos o direito de acesso ao Ensino Superior e somos maioria, questionamos: quem são essas mulheres "maioria" no ensino superior? $\mathrm{O}$ acesso à formação também se revela quando verificamos a presença feminina enquanto profissional do ensino superior? Qual o lugar ocupado pela mulher-docentediscente-pesquisadora no âmbito do ensino superior? Quais as características dos fazeres de mulheres-docentes-discente-pesquisadoras-nordestinas?

\section{O Ser mulher: construção histórica colonial da desigualdade de gênero}

A construção hierárquica histórico-cultural ocidental (em específico desde a Grécia Antiga, o berço da filosofia ocidental) de características dicotômicas destinadas aos gêneros feminino e masculino, foram baseadas numa noção de desigualdade natural, sendo a mulher, vista como "um homem incompleto" pelos gregos, portadora de certos vícios e irracionalidade, destinada à reprodução, incapaz de atuar na vida pública da pólis, e por estes motivos, deveria ser resguardada apenas aos limites do cuidado do oikos (lar) e da reprodução sexual, sob a tutela do patriarkhes (patriarca, chefe da família). O homem representava o ideal de ser humano, construído a partir da noção de força e virilidade do macho, assim, afirma Aristóteles (2006, p. 27): “O macho está acima da fêmea [...] qualquer que seja a idade da mulher, o homem deve conservar sua superioridade.”..

Nos voltando para a modernidade colonial, na colonização das Américas e do Caribe, a noção de superioridade do homem-branco-europeu pertencente a uma "cultura civilizada", plenamente humano, que tinha como missão "civilizar" povos selvagens destituindo-os de sua humanidade, como coloca Maria Lugones (2014, p. 936), que os colonizadores criaram

uma distinção dicotômica, hierárquica entre humano e não humano foi imposta sobre os/as colonizados/as a serviço do homem ocidental. Ela veio acompanhada por outras distinções hierárquicas dicotômicas, incluindo aquela entre homens e mulheres. [...] Os povos indígenas das Américas e os/as africanos/as escravizados/as eram classificados/as como espécies não humanas. 
Junto dos colonizadores europeus e sua categorização de humanos e não-humanos, vem também a generificação dos povos colonizados como uma categoria natural e universal. Sendo o gênero masculino e feminino criado a partir da categoria de essência "macho e fêmea", o macho/homem é a perfeição, e a fêmea/mulher sua inversão. Mas, os colonizados por não se encaixarem na categoria de igual perante os colonizadores, não serão vistos como homens e mulheres, pois como coloca Lugones (2014, p. 937) "Machos tornaram-se não-humanos por não-homens, e fêmeas colonizadas tornaram-se não-humanas por não-mulheres." Sendo a mulher branca vista como um Outro do homem, o inessencial, como coloca Simone de Beauvoir em O Segundo Sexo (2009), então, a mulher ameríndia, africana, racializada, será vista como o Outro do Outro ${ }^{7}$, onde não se tem lugar, um espaço vazio e invisível, incapaz de produzir conhecimento.

Mediante essa construção de poder da colonialidade sobre os gêneros, ocorreu a negação do reconhecimento da humanidade de mulheres latinas-americanas e africanas enquanto sujeitas $^{8}$ humanas e produtoras de conhecimentos e epistemologias, quando o reconhecimento para as mulheres europeias era difícil, para nós latinas-americanas era basicamente impossível. Ainda que hajam registros históricos de mulheres europeias intelectuais em espaços acadêmicos, como a filósofa Hypatia de Alexandria (370-413 d. C.) que sucedeu o filósofo Plotino na Academia de Alexandria enquanto professora. Também de filósofas cristãs na Idade Média, como exemplo Hildegarda de Bingen (1098-1179), Marguerite Porete (1250-1310) e Christine de Pizan (1364-1430), como grandes figuras cultas no período medievo, não as encontramos nas grades curriculares dos cursos de filosofia.

Mesmo havendo figuras femininas que produziram e produzem conhecimentos filosóficos e científicos, não vemos essa presença feminina nas grades curriculares das academias, muito menos quando buscamos mulheres latinas-americanas, ameríndias ou africanas, tal fato não se dá pela ausência na produção filosófica ou científica, mas pela domínio colonial masculino sobre os espaços de produção de conhecimento e classificação de análise sobre o que merece ser reconhecimento como filosofia ou ciência. Grada Kilomba

\footnotetext{
${ }^{7}$ Para Grada kilomba as pessoas racializadas negras e indígenas são constituídas a partir da perspectiva dos brancos como as/os Outras/os em antagonia ao Eu, assim, “A/O 'Outra/o' não é 'outra/o' per se; ela/ele torna-se através de um processo de absoluta negação" (KILOMBA, 2019, p. 38). Sendo a mulher branca a Outra do homem branco, a mulher negra e indígena serão categorizadas como a Outra da Outra, por um processo de negação dupla, como não-mulheres por não-humanas.

${ }^{8}$ Grada Kilomba (2019) mostra que a língua possui uma dimensão de demarcação de poder, - principalmente a língua portuguesa carregada do colonialismo patriarcal - contrário ao termo subject no inglês que é um termo neutro, sem gênero, a língua portuguesa não permite variação do termo sujeito que é colocado e reduzido ao gênero masculino, não possuindo variação para o feminino sujeita ou para identidades LGBTQI+.
} 
"Descolonizando o Conhecimento"9 aborda sobre como o conhecimento também reproduz relações de poder racial e de gênero pois a epistemologia (do grego episteme que é conhecimento e logos que é ciência) determina:

1. (os temas) quais temas ou tópicos merecem atenção e quais questões são dignas de serem feitas com o intuito de produzir conhecimento verdadeiro. 2 . (os paradigmas) quais narrativas e interpretações podem ser usadas para explicar um fenômeno, isto é, a partir de qual perspectiva o conhecimento verdadeiro pode ser produzido. 3. (os métodos) e quais maneiras e formatos podem ser usados para a produção de conhecimento confiável e verdadeiro. Epistemologia, como eu já havia dito, define não somente como, mas também quem produz conhecimento verdadeiro e em quem acreditarmos. É comum ouvirmos o quão interessante nosso trabalho é, mas também ouvimos o quão específico ele é: "Isso não é nada objetivo!", "Você tem que ser neutra...", "Se você quiser se tornar uma acadêmica, não pode ser pessoal". "A ciência é universal, não subjetiva". "Seu problema é que você super interpreta a realidade, você deve se achar a rainha da interpretação!" Tais comentários ilustram uma hierarquia colonial, pela qual pessoas Negras e racializadas são demarcadas. Assim que começamos a falar e a proferir conhecimento, nossas vozes são silenciadas por tais comentários, que, na verdade, funcionam como máscaras metafóricas. Tais observações posicionam nossos discursos de volta para as margens como conhecimento 'des-viado' e desviante enquanto discursos brancos permanecem no centro, como norma. Quando eles falam, é científico, quando nós falamos, não é científico. Universal/específico; objetivo/subjetivo; neutro/pessoal; racional/emocional; imparcial/parcial; eles têm fatos, nós temos opiniões; eles têm conhecimento; nós, experiências. Nós não estamos lidando aqui com uma "coexistência pacífica de palavras" (Jacques Derrida, Positions, University of Chicago Press, Chicago, 1981), mas sim com uma hierarquia violenta que determina quem pode falar.

Assim, a luta por reconhecimento da mulher-pesquisadora brasileira e nordestina nos espaços intelectuais é árdua, pois enfrentamos uma supremacia do discurso masculino-europeu. Mas, nosso espaço no Brasil, vem sendo conquistado por figuras como a ilustre Nísia Floresta que no seu livro Direitos das Mulheres, Injustiça dos Homens (1989), defende a educação igualitária entre os gêneros, assim, como fundou o Colégio Augusto em 1838, ensinando as mesmas disciplinas para meninos e meninas. Mesmo com figuras como Nísia defendendo a educação igualitária entre os gêneros, só foi permitido pelo governo imperial do Brasil que as mulheres de famílias abastadas frequentassem as universidades apenas em 1879, as candidatas solteiras deveriam apresentar uma licença de seus pais; já as casadas, o consentimento por escrito de seus maridos (FERNANDES, 2019). Dessarte, o ensino intelectual era restrito a um pequeno grupo de mulheres brancas de classe dominante.

\footnotetext{
${ }^{9}$ Grada Kilomba realizou uma palestra "Descolonizando o conhecimento", que foi transcrita pelo Instituto Goethe. Disponível em: https://goo.gl/sYWwY1. Acesso em: 02 de jul. de 2020.
} 
Mundialmente, a primeira onda do feminismo se move em defesa da inserção da mulher branca nas esferas públicas, como nos cursos superiores, mas como citado, esses movimentos eram movidos por mulheres brancas burguesas que universalizam a categoria "mulher", sem considerar as diversas identidades. E enquanto mulheres brancas lutavam por direitos salariais iguais e para ingressarem nas universidades, as mulheres negras viviam em condições subhumanas trabalhando desde o período escravocrata sem nenhuma remuneração, direito ou visibilidade de suas necessidades, como problematiza a filósofa brasileira Djamila Ribeiro (2017, p. 13) sobre o feminismo hegemônico que faz uma

[...] universalização da categoria mulher. Esse debate de se perceber as várias possibilidades de ser mulher, ou seja, do feminismo abdicar da estrutura universal ao se falar de mulheres levar em conta as outras intersecções, como raça, orientação sexual, identidade de gênero, foi atribuído mais fortemente à terceira onda do feminismo.

No Brasil, somente no final do século XIX, as mulheres foram autorizadas a frequentarem o Ensino Superior. Ainda assim, a primeira mulher a entrar na universidade, foi uma mulher branca filha de um comerciante rico, a Rita Lobato Velho Lopes, vindo a se formar, em 1887, na Faculdade de Medicina, no estado da Bahia; e a primeira mulher negra, Enedina Alves Marques, ingressou na universidade 66 (sessenta e seis) anos após, em 1940 na Faculdade de Engenharia na Universidade do Paraná, sendo a primeira mulher negra no Brasil, em 1945, a concluir uma faculdade, e a primeira mulher engenheira.

Essa realidade acadêmica tem mudado um pouco no atual contexto brasileiro. De acordo com dados de 2016 da Estatísticas de Gênero: Indicadores Sociais das Mulheres no Brasil, divulgado pelo Instituto Brasileiro de Geografia e Estatística - IBGE, que realizou um estudo a partir da população maior de 25 anos de idade com ensino superior completo. As mulheres somam $23,5 \%$, e os homens, $20,7 \%$, e quando comparamos com dados de homens e mulheres de cor preta ou parda, os percentuais são bastante inferiores: $7 \%$ entre os homens e 10,4\% entre mulheres. Assim, também foi observado que mesmo que as mulheres estejam em maior número com o ensino superior completo, essa realidade não reflete na igualdade/equidade salarial no mercado de trabalho. (GRANDA, 2020).

Mesmo que, nós mulheres, tenhamos o direito de acesso ao Ensino Superior, questionamos: onde está nosso reconhecimento e a justiça de gênero/raça no mercado de trabalho? E quanto à presença feminina enquanto profissional do ensino superior? Qual o lugar ocupado pela mulher-docente-discente-pesquisadora no âmbito do ensino superior? 
Em relação ao primeiro questionamento, a divisão do trabalho brasileiro foi realizada com base na exploração escravagista de pessoas negras, e na divisão de "papéis de gênero", que como colocam as pensadoras Arruzza, Bhattacharya e Fraser (2019, p. 106), o trabalho do cuidado e da reprodução social foi feminizada e "[...] a sociedade capitalista não confere nenhum valor a esse trabalho, mesmo dependendo dele.”, assim, nós mulheres (de acordo com o recorte de classe, raça, etnia, identidade de gênero, como as mulheres trans/travestis) passamos a ocupar lugares menos remunerados/não-remunerados no mercado de trabalho. Do mesmo modo, quando observamos o lugar da mulher docente na Universidade, segundo Censo da Educação Superior de 2016 (BRASIL, 2020), que realizou um questionário de gênero e raça nas universidades públicas e privadas pelo Instituto Nacional de Estudos e Pesquisas Educacionais Anísio Teixeira - INEP, em relação à docência de pós-graduação, os homens brancos com doutorado somam 13.198, o que representa 24\%; as mulheres brancas na docência somam pouco mais de 10 mil, $19 \%$ do total de 53.995 professores nos cursos de doutorado, mestrado e especialização, e as mulheres pretas e pardas com doutorado, que formam o grupo das negras, não chegam a $3 \%$ do total.

Devido essas concepções históricas da atribuição do cuidado ao feminino, a história da pedagogia tenha sido marcada pela presença das mulheres, como revelam dados do Censo Escolar 2018, divulgado pelo Ministério da Educação, cerca de 80\% dos 2,2 milhões de docentes da educação básica brasileira são do gênero feminino. Porém, quando há um crescimento no status quo da profissão docente e na mudança da área de atuação como o curso de Filosofia, menor os números de cargos ocupados por mulheres consequência da estrutura cisheteropatriarcal $^{10}$, segundo dados de 2017 do Inep- Relatório Sìntese Filosofia, no curso de licenciatura em filosofia as mulheres somam 33,20\% de concluintes, e no bacharelado somam 26,10\% (ARAÚJO,2020).

\section{Nuances do contexto do Rio Grande do Norte - RN, da UERN, Campus Caicó, Curso de Licenciatura em Filosofia}

Evidenciamos o pioneirismo do Rio Grande do Norte na história de superação e conquista de espaços pelas mulheres: a notável pensadora Nísia Floresta, representante dos

\footnotetext{
${ }^{10}$ Para Carla Akotirene (2019, p. 118) “O patriarcado é um sistema político modelador da cultura e dominação masculina especialmente contra as mulheres [...] que impõe papéis de gênero desde a infância baseados em identidades binárias, informadas pela noção de homem e mulher biológicos, sendo as pessoas cisgêneras aquelas que não cabíveis , necessariamente, nas masculinidades e feminilidades duais hegemônicas".
} 
primórdios do movimento feminista no Brasil; Auta de Souza, grande poetisa potiguar; Alzira Soriano, a primeira mulher eleita prefeita no Brasil e na América Latina; Celina Guimarães, primeira mulher a votar, representam a sagacidade da mulher nordestina e potiguar.

Contudo, no âmbito da UERN, embora o número de mulheres docentes-pesquisadoras venha crescendo a cada ano, ainda se verificam diferenças de gênero com percentuais variados a depender da área de atuação, apontando para a hipótese de que ainda existem áreas que são preferidas e construídas histórica e socialmente pelo viés das subjetividades dos sujeitos masculino e feminino. Compõem o quadro atual da UERN, 940 (novecentos e quarenta) docentes, desse 496 (quatrocentos e noventa e seis) são homens e 444 (quatrocentos e quarenta e quatro) são mulheres.

No Campus Caicó, a presença das mulheres como docentes e pesquisadoras em IES, é exemplo dessa tendência de inserção nacional da mulher nas IES. No quadro docente atual dos três cursos ofertados: Enfermagem, Filosofia e Odontologia, dos 63 (sessenta e três) docentes, 36 (trinta e seis) são mulheres e 27 (vinte e sete) são do gênero masculino.

A partir dessa realidade, podemos tomar como exemplo da construção histórica e social por área pelo viés do masculino e feminino, o nosso Departamento de Filosofia, no qual somos 12 (doze) docentes, sendo que apenas 03 (três) são mulheres, contrariamente, no Curso de Enfermagem, verifica-se de um total de 24 (vinte e quatro) docentes, apenas 04 (quatro) são homens e 20 (vinte) são mulheres. Sendo que a história do Curso de Enfermagem, contrário ao Curso de Filosofia, possui um caminho marcado pela trajetória da figura feminina, pois foi construída sob a ideia do cuidado, que está intimamente relacionada à figura do feminino, como na Pedagogia, por exemplo.

Desse modo, quando lançamos um olhar para os números de egressos/as do Curso de Licenciatura em Filosofia de Caicó no período de 2002 a 2017.2 $2^{11}$, do total de 211 (duzentos e onze) estudantes diplomados/as, 92 (noventa e dois) são do sexo feminino e 119 (cento e dezenove) são do sexo masculino revelando uma tendência equilibrada a considerar a evolução formativa no período de 19 (dezenove) anos de oferta do referido Curso. Contudo, ao buscarmos perceber a continuidade da formação, a qual possibilitaria a ascensão da mulher à condição de docente-pesquisadora nas IES, verificamos que das egressas do Curso de Filosofia em Caicó, apenas 05 (cinco) deram continuidade à formação em nível de pós-graduação, mestrado.

\footnotetext{
${ }^{11}$ Dados elaborados e cedidos pela secretaria do Departamento de Filosofia de Caicó - DFI, em setembro de 2018.
} 
Nessa perspectiva, é crucial evidenciar sobre a presença feminina no Programa de Pósgraduação em Filosofia - PROF-FILO ${ }^{12}$, Polo Caicó, o qual encontra-se em processo de formação de sua quarta turma. Verificamos ${ }^{13}$ que dos/as 27 (vinte e sete) estudantes, apenas 08 (oito) são mulheres, correspondente ao percentual de $29 \%$ (vinte e nove por cento), evidenciando que a mulher na área da filosofia encontra dificuldades para dá continuidade à sua formação em nível de pós-graduação.

Tais dados tem nos inquietado e nos levado a questionar: que contextos dificultam a continuidade da formação feminina, a considerar o lócus do citado Curso de Filosofia de Caicó? De que maneira o feminino é presença na formação da/do licenciado/a em Filosofia no Campus Caicó? Como viés para problematizar esses questionamentos lançamos um olhar ao currículo presente nossos Projetos Pedagógicos de Curso - PPCs de Filosofia/UERN/Campus Caicó (BRASIL, 2012 - 2018), nos quais, percebemos, com raras exceções, que a presença da mulherfilósofa é praticamente invisível na bibliografia básica dos PPCs do Curso, encontramos apenas duas: Hannah Arendt e Nancy Fraser. Tais aspectos poderiam ser considerados na visível dificuldade de inserção à continuidade da formação para a mulher-docente-pesquisadora na área da Filosofia? Ponderando sobre esse aspecto, Tolentino (2017, s/p) assim se posiciona:

[...] seja na educação básica ou na formação superior, o quanto alimentamos as opressões de gênero ao transmitirmos um saber que parece interditado às mulheres, posto que não as escutamos, totalmente identificado com o sucesso de mais de vinte séculos de misoginia epistêmica. Isto é, do genocídio epistêmico das mulheres, operado ao longo de toda a história norte-ocidental unívoca heteropatriarcal hegemônica, através do apagamento e da total desqualificação da capacidade das mulheres de produzir conhecimento. Elas foram assim restringidas e reduzidas ao nível do privado, do familiar, excluídas do âmbito público, político e epistêmico, aprisionadas na doxa, reduzidas ao senso comum.

A autora considera que embora a filosofia se identifique como área de superação ao senso comum, em relação às mulheres tem se constituído, historicamente, em campo de consolidação do poder masculino, branco e de classe dominante, que produz o silenciamentos das vozes femininas tornando a figura da mulher filósofa invisível. É mister considerar,

\footnotetext{
${ }^{12}$ Conforme Portaria Normativa do MEC n. 17 de 28/12/09, o Mestrado Profissional em Filosofia (PROF-FILO) é um programa de pós-graduação destinado a ofertar curso de mestrado a professores de filosofia do ensino médio ou fundamental, na modalidade profissional, em rede e com abrangência nacional. Disponível em: http://www.humanas.ufpr.br/portal/prof-filo/prof-filo/ Acessado em: 28/06/2019.

${ }^{13}$ Dados elaborados e cedidos pela secretaria do PROF-FILO/Polo Caicó, em junho de 2019.
} 
também, a construção histórica de cada área de formação que se configuram como áreas de cunho masculino e/ou feminino.

Para além dos números que revelam uma tendência de inserção e equivalência quantitativa do acesso e da presença da mulher-docente-pesquisadora nas IES, reconhecemos que a questão é bem mais complexa, com implicações históricas, culturais e sociais que tecem na desigualdade e nas relações de subjetividade nos espaços da IES, a constituição do ser mulher-docente-discente-pesquisadora. Em pleno século XXI, ainda persistem o enfrentamento incorporado pelo relato e registro de experiências das mulheres educadoras e educandas nas lutas pelo reconhecimento social na universidade pública. Essa questão, necessita ser bem mais problematizada, pois os mecanismos de segregação das ações das mulheres passam por gestos mínimos cotidianamente, gestos simples e significantes implícitos nas relações sociais internas e externas que se estabelecem entre homens e mulheres desde o contexto doméstico ao acadêmico, produzindo processos de subjetivação que exigem um estado de atenção permanente para que o lugar ocupado pelas mulheres-docentes-discentes-pesquisadoras não continue a ser negado de maneira velada, mesmo com a presença quantitativa dessas nas IES. , vindo a se constituir e se revelar como "algo menor" ${ }^{14}$ dentro das IES.

\section{Mulher-docente-discente-pesquisadora: experiências na Escola Pública}

\section{Perspectiva mulher-docente-pesquisadora}

Em que pesem os aspectos históricos e sociais supracitados, como se situa a nossa trajetória de luta como mulher-docente-pesquisadora-nordestina-potiguar dentro desse contexto? Se constitui na construção de uma identidade feminina como movimento de luta, militância e resistência auto formativa que nos move e nos comove pelas experiências vividas, especialmente junto às atividades de ensino, pesquisa e extensão em projetos na parceria com a escola pública desde o ano de 2004. No contexto atual, nossas ações de mulher-docentepesquisadora se desenvolvem em escolas da educação básica no município de Caicó e de

\footnotetext{
14 Termo utilizado por Gallo (2008, grifos do autor), a partir do pensamento de Deleuze e Guattari (1992), para referir-se à uma linguagem marginal que se construía na Alemanha em detrimento da língua culta: “[...] à tona o conceito de educação menor, como dispositivo para pensarmos as tentativas que ensaiam práticas, que se amparam em ideais consideradas fora do contexto das políticas atuais, tais como: amor, afeto, transformação, igualdade, singularidade, as quais, muitas vezes, encontram grande resistência tanto na filosofia como na pedagogia." (CIRINO, 2016, p. 154).
} 
cidades circunvizinhas. Ser docente-pesquisadora em temas singulares e ainda marginais dentre as áreas de Filosofia e Educação, tais como: filosofia com crianças, igualdade de inteligências, memória, identidade, formação social do sujeito, Educação Crítica-Emancipatória e Interacionismo Simbólico, Estudos de Identidade e sobre as Filósofas Mulheres, respectivamente, na nossa realidade, é ser seduzida pela escola, pelas crianças e jovens e buscar conquistar a cada dia, pois que se trata de temas errantes, estrangeiros na filosofia e na educação e que encontram resistências nas duas áreas. Contudo, na relação com a escola, percebemos que esse fazer da experiência atravessa a escola e transborda para as salas de aulas dos/das professores/as envolvidos/as da educação infantil e do ensino fundamental.

Nessa militância citamos, ainda, dois primeiros obstáculos a serem superados, o primeiro trata-se do investimento na própria formação continuada, visto ser a titulação em nível de Pós-Graduação que cria as condições legais para a docente-mulher-pesquisadora ascender ao nível de docente-pesquisadora na IES; o segundo, refere-se ao distanciamento geográfico da região em relação aos grandes centros e a escassez de vagas em programas de pós-graduação na região é outro dos grandes obstáculos a serem enfrentados. Cita-se no nosso Departamento de Filosofia, desde sua criação, período 2002-2017, das 92 (noventa e duas) mulheres que se graduaram em Filosofia, apenas 05 (cinco), até o momento da escrita desse texto, concluiu PósGraduação em nível de Mestrado. Evidenciamos quanto à oferta do PROF-FILO, das 08 (oito) mulheres que compõem o quadro atual das 04 (quatro) turmas em processo formativo, somente 06 (seis) são oriundas da formação no DFI/Campus Caicó.

Nesse sentido, a possibilidade que tivemos de fazer doutorado interinstitucional em parceria entre a UERN e a Universidade do Estado do Rio de Janeiro - UERJ; Doutorado em Memórias, Linguagem e Sociedade pela Universidade Estadual do Sudoeste da Bahia - UESB, respectivamente, constituiu-se em oportunidade de superação desses primeiros obstáculos e contribuiu para a criação do Mestrado Profissional - PROF-FILO, Polo Caicó/UERN. Através do PROF-FILO, estamos possibilitando Pós-Graduação para 08 (oito) mulheres, as quais compõem as 04 (três) três primeiras turmas.

Ainda, registram-se, a realização de diversos eventos na UERN com a participação de docentes da UERJ e da UESB promovendo a renovação e troca de saberes e oportunidade de produções acadêmicas, pois que, um terceiro aspecto à ser considerado é a dificuldade de manutenção de um nível de produção acadêmica, tanto de publicação de livros e artigos, periódicos qualis, que faça jus ao perfil de competitividade para a captação de recursos junto às agências financiadoras, em vista de manter o fluxo de bolsas de pesquisas, as quais, 
especialmente, em um contexto regional de sérias desigualdades sociais, são de fundamental importância para a manutenção da pesquisa.

É a partir dessas experiências, vividas e rememoradas na nossa trajetória profissional, que pulsa contradições e paradoxos, que o ser mulher-docente-pesquisadora-nordestinapotiguar significa transitar entre a consciência do real e a resistência. É ter e manter a utopia e buscar alternativas para superar a distância entre os grandes centros de produção científica e tecnológica e a localização geográfica da região. Significa abrir brechas, como poetizado na epígrafe, para que seja possível, através do ensino, pesquisa e extensão, poder se deslocar aos grandes centros de pesquisas, mas também aos centros circunvizinhos para buscar parcerias. Ser mulher-docente-pesquisadora-nordestina-potiguar, é então, ser desbravadora de mundos para nós mesmas e para nossos/as estudantes, e, literalmente, como expressa um dito popular nordestino: "tirar leite de pedra."

Assim, ser mulher-docente-pesquisadora-nordestina-potiguar é, sobretudo, ser grávida de inquietações, é acolher às inquietações dos estudantes e até buscar provocá-las, fazê-los/as acreditar que apesar das dificuldades sociais nas quais se inserem os contextos formativos do $\mathrm{RN}$, é possível encontrar alternativas de concretização de espaços de formação, de troca e construção de saberes. É buscar o esvaziamento do saber, assumindo a humildade da experiência do "não saber" e entrar, junto com os/as estudantes, no processo de busca pelo saber construído coletivamente.

E, por último, e talvez o aspecto mais importante que desejamos ressaltar como mulherdocente-pesquisadora-potiguar, é que as possibilidades de pesquisar e de significação das teorias estudadas, na nossa realidade, nascem e adquirem significados a partir e em processo no espaço da escola pública. É no encontro com os fazeres e provocações da/na escola pública que as nossas inquietações tomam forma, desenvolvem-se e retornam à escola, alimentadas pelo processo da pesquisa e extensão, para continuar pensando e se movimentando entre a escola de educação básica e a universidade. Sem essas interlocuções, a pesquisa na minha perspectiva de uma pesquisadora que transita entre a filosofia e a educação não encontra sentido, não ecoa em mim, não reverbera. 
Mulher-discente - pesquisadora: da Escola Pública à Universidade Pública

Quais os enfrentamentos que a mulher-discente-pesquisadora passa desde o ensino médio até se engajar numa universidade? Primeiramente, ingresse ${ }^{15}$ na universidade por meio de cotas para estudantes de baixa renda de escola pública, por pertencer a uma família pobre da zona rural. Mas, mesmo com empecilhos de classe e região, sempre tive a figura de minha mãe muito forte e presente no incentivo à minha formação educacional e a busca por conhecimento, para que eu tivesse acesso às oportunidades que ela não teve. Por isso sempre sonhei em romper com o apagamento das experiências das mulheres nordestinas, que são representadas pelas mídias brancas coloniais como seres "ignorantes" e "brutas", incapazes de produzir conhecimento.

Assim, conclui meu ensino médio na escola Estadual Basílio Batista de Araújo, na época fui presidenta do conselho estudantil e fiz parte do movimento estudantil de secundaristas. Em 2017 tentei o Exame Nacional do Ensino Médio - ENEM, e ingressei no Curso de Licenciatura em Filosofia, na UERN, Campus Caicó, no ano de 2018, sendo eu, a primeira mulher da família a ingressar em um curso superior (e espero que venham muitas depois de mim). Vinda de uma família sem capital cultural, porém, com conhecimentos ancestrais empíricos.

Ao chegar à universidade e ser recebida carinhosamente por todas as professoras e professores, as dificuldades que nós estudantes enfrentamos na Universidade Pública Estadual, desde a escassez de bolsas até a as dificuldades financeiras para se manter na cidade locus do campus, são os maiores desafios para permanecer na universidade, o maior problema na graduação brasileira não é somente o ingresso na universidade, mas a permanência.

Mediante os obstáculos dos cortes orçamentários que vem afetando nossa Universidade Estadual ao longo de sua existência por parte dos governos estaduais, somados aos cortes federais nas bolsas de pesquisa científica e nas bolsas de iniciação à docência (19,8 bilhões cortados da educação ${ }^{16}$ ), e as dificuldades financeiras que cada estudante enfrenta, dificultam bastante a produção e a pesquisa científica. Por vezes, nos desdobramos para cumprir leituras, trabalhos acadêmicos, compras de materiais de estudo, transportes e custeios em eventos

\footnotetext{
${ }^{15}$ Fala na primeira pessoa da autora desse texto para relatar sua trajetória pessoal de mulher-discente-pesquisadora.

${ }^{16}$ Jornalistas Livres. Corte de $\mathbf{R}$ \$ 19,8 bilhões no Ministério da Educação no orçamento para 2020. 19 de jan. de 2020. Disponível em: https://jornalistaslivres.org/corte-de-r-198-bilhoes-no-ministerio-da-educacao-noorcamento-para-2020/. Acesso em 09 de jul. de 2020.
} 
acadêmicos, e muitas vezes, pela ausência de remuneração na pesquisa científica precisamos trabalhar e abrir mão da dedicação acadêmica.

Assim, percebemos que a busca pelo conhecimento é um caminho árduo, mas quanto mais se conhece, mais se quer conhecer. E quando em meus estudos, me deparei com as figuras masculinas de Sócrates, Aristóteles, São Tomás de Aquino, Hobbes, Maquiavel, Nietzsche, Karl Marx, Sartre, notei que não havia nenhum nome feminino na bibliografia do Curso de Filosofia, e no livro didático que utilizei durante o ensino médio encontrei apenas uma notinha de rodapé no livro didático sobre Simone de Beauvoir, eu me perguntei “onde estão as mulheres na Filosofia?" e a partir dessa inquietação, iniciei investigações sobre a temática da invisibilidade da mulher na filosofia e na ciência.

\section{Considerações finais}

Então, se as mulheres filósofas estão presentes na história e vivem por meio de seus pensamentos, por qual motivo não são estudadas na academia? Qual a importância do reconhecimento da mulher pensadora latina-americana, brasileira? Primeiro, vivemos e convivemos em sociedade, por isso produzimos conhecimentos, filosofias e ciências, diversas epistemologias por experiências plurais, e por nós mulheres lutarmos por reconhecimento de nossa dignidade humana, enquanto ser pensante como qualquer outro da espécie, dotadas de racionalidade e memórias, e por isso trocamos sentidos e significados em nossas interações e produções. Para tanto, produzimos filosofia, ciência e arte no anonimato por muito tempo, como diz Virgínia Woolf (1928, p. 59), “Anônimo, que escreveu tantos poemas sem assiná-los, foi muitas vezes uma mulher".

Queremos o reconhecimento das nossas produções intelectuais, das nossas epistemologias, esfacelando a estrutura reguladora de poder que determina quem pode falar. Nós mesmas iremos contar nossas histórias, a partir da pluralidade de experiências, valorizando a interdependência, pois viver é conviver e comunicar, comunicar é "pôr em comum", por isso a necessidade do reconhecimento social, para que se possa ser sujeito e ter um Lugar de Fala na sociedade. Para produzirmos filosofia e ciência em comunidade, e para que seus sentidos e significados possam conduzir, interpretar, interagir e modificar a nossa realidade.

Enfim, ser mulher-docente-discente-pesquisadora-nordestina-potiguar é encontrar possibilidades, e diante da mesmice acadêmica, pesquisar pelo viés e singularidade da experiência que legitima e transforma os processos de pesquisar dentro da nossa realidade, em 
acontecimento. Nesse sentido, ressaltamos as parcerias com as mulheres professoras e com as muitas mulheres presentes na gestão das escolas públicas por onde transitamos no RN. Sem essa cumplicidade e a utopia que compartilhamos, a constituição dessa mulher-docentediscente-pesquisadora não seria possível. Isso significa que o nosso fazer, enquanto mulheresdocentes-discentes, se fortalece e se amplia em parceria, especialmente, com outras mulheres.

Portanto, ser mulher-docente-discente-pesquisadora-potiguar é, metaforicamente, ser fonte de resistência, resiliência para superação das situações adversas tão pertinentes aos povos nordestinos, é semear na aridez da terra potiguar e trabalhar, insistentemente, aguardando com perseverança a tão esperada chuva, benção da/para nossa região, a qual provocará a alegria da sangria dos açudes, nesse caso da construção de oportunidades para o desenvolvimento do conhecimento através do ensino, da pesquisa e extensão na universidade e na escola pública.

Por fim, uma última epígrafe de um fragmento do poema da nossa já citada e estimada poetisa potiguar Marize Castro ao escrever sobre nós mulheres ao Diário de Natal, em 1999, afirma o que acontece quando uma mulher resiste e se permite encontrar o seu lugar: "[...] o que há de mais solitário se alarga. [...] ela se arqueia na esperança que o amor, quando novamente acontecer, não traga algemas. Traz na língua o perdão e suas chamas.”

\section{Referências}

AKOTIRENE, Carla. Interseccionalidade. São Paulo: Sueli Carneiro; Pólen Livros, 2019.

ARISTÓTELES. De Anima. Apresentação, tradução e notas de Maria Cecília Gomes dos Reis. São Paulo (SP): Ed. 34, 2006.

ARAÚJO, Carolina. Rede Brasileira de Mulheres Filósofas: Concluintes da Graduação em Filosofia no Brasil por Sexo (Licenciatura e Bacharelado): 2017. Disponível em: https://www.filosofas.org/post/concluintes-da-gradua\%C3\%A7\%C3\% A3o-em-filosofia-nobrasil-por-sexo-licenciatura-e-bacharelado-2017. Acesso em 03 de jul. de 2020.

ARRUZZA, Cinzia; BHATTACHARYA, Tithi; FRASER, Nancy. Feminismo para os 99\% um manifesto. São Paulo: Boitempo, 2019.

BEAUVOIR, Simone. O segundo sexo. Rio de Janeiro: Editora Nova Fronteira, 2009.

BRASIL. Universidade do Estado do Rio Grande do Norte - UERN. Projeto Pedagógico de Curso. Pró-Reitoria de Ensino de Graduação - PROEG. Curso de Licenciatura em Filosofia. Campus Caicó - CAC. 2012 - 2017 - 2018.

. Instituto Nacional de Estudos e Pesquisas Educacionais Anísio Teixeira - INEP. Censo

da educação superior: 2012. Resumo técnico. Brasília: Disponível em: 
<http://download.inep.gov.br/educacao_superior/censo_superior/resumo_tecnico/resumo_tec nico_censo_educacao_superior_2011.pdf.> Acesso em: 24 out. 2018.

BACKES, Vanessa Ferreira; THOMAZ, Jean Rodrigo; SILVA, Fabiana Ferreira da. Mulheres docentes no ensino superior: problematizando questões de gênero na Universidade Federal do Pampa. Disponível em: Cad. Ed. Tec. Soc., Inhumas, v.9, n.2, p. 166-181, 2016. D.O.I http://dx.doi.org/10.14571/cets.v9 .n 2.166-181

CIRINO, M. R. D. Filosofia com Crianças: cenas de experiências em Caicó (RN), Rio de Janeiro (RJ) e La Plata (Argentina). Rio de Janeiro/RJ: NEFI, 2016 (Coleção Teses e Dissertações: 2).

CYRULNIK, B. Os patinhos feios. Tradução Mônica Stahel. São Paulo: Martins Fontes, 2004.

DELEUZE, Gilles ; GUATARRI, Félix. O que é a filosofia? São Paulo: Editora 34, 1992.

Fundação Telefônica Vivo. $80 \%$ dos docentes da educação básica brasileira são mulheres. Disponível em: http://fundacaotelefonica.org.br/noticias/80-dos-docentes-da-educacao-basicabrasileira-sao-mulheres/. Acesso em: 22 de abr. de 2020.

FERNANDES, Fernanda. A história da educação feminina. Multi Rio e a mídia educativa da cidade. 07 de mar. de 2019. Disponível em:

http://www.multirio.rj.gov.br/index.php/leia/reportagens-artigos/reportagens/14812-ahist\%C3\%B3ria-da-educa\%C3\%A7\%C3\%A3o-feminina. Acesso em 03 de jul. de 2020.

FLORESTA, Nísia. Direitos das mulheres e injustiça dos homens. São Paulo: Cortez, 1989.

FERREIRA, Lola. Menos de 3\% entre docentes da pós-graduação, doutoras negras desafiam racismo na academia. Gênero e número. 20 de jun. de 2018. Disponível em: http://www.generonumero.media/menos-de-3-entre-docentes-doutoras-negras-desafiamracismo-na-academial. Acesso em: 23 de abr. de 2020.

GRANDA, Alana. IBGE: mulheres ganham menos que homens mesmo sendo maioria com ensino superior. Agência Brasil, Rio de Janeiro, 07 de mar. de 2018. Disponível em:https://agenciabrasil.ebc.com.br/geral/noticia/2018-03/ibge-mulheres-ganham-menos-quehomens-mesmo-sendo-maioria-com-ensino-superior. Acesso em: 23 de abr. de 2020.

KILOMBA, Grada. Memórias da plantação episódios de racismo cotidiano. Rio de Janeiro: Editora de Livros Cobogó, 2019.

LINDEMANN, Hilde. An Invitation to feminist Ethics, San Francisco: McGraw-Hill, 2006.

LUGONES, María. Rumo a um feminismo descolonial. Revista Estudos Feministas, v. 22, n. 3, p. 935-952, 2014.

MARGUTTI, Paulo. Nísia Floresta, uma brasileira desconhecida: feminismo, positivismo e outras tendências. Porto Alegre: Editora Fi, 2019. 
MEAD, G.H. Mente, self e sociedade. MORRIS, C. W. (Org.); [tradução Maria Silva Mourão]. Aparecida, SP: Idéias \& Letras, 2010.

MEDEIROS, Shirlene Santos Mafra. Memória e Identidade Social da Formação Docente em Rio de Contas-BA, nas décadas de 1920 a 1960: reminiscências das educadoras e educadores da Cátedra à Universidade. 2016. 337 p. Tese (Doutorado) - Curso de Filosofia, Programa de Pós-Graduação em Memória: Linguagem e Sociedade, Universidade do Estadual do Sudeste da Bahia, Bahia, 2016.

PACHECO, Juliana. Mulher e filosofia: as relações de gênero no pensamento filosófico. Porto Alegre: Editora Fi, 2015.

RIBEIRO, Djamila. O que é Lugar de Fala? Belo Horizonte: Editora Letramento, 2017.

SCHIEBINGER, L. O feminismo mudou a ciência? São Paulo: EDUSC, 2001.

TOLENTINO, Joana. Filósofas: invisibilidade e silenciamento. Revista Sísifo. 2017, n. 6, v .1 .ISSN2359-3121 Disponível em: http://www.revistasisifo.com/2017/11/filosofasinvisibilidade-e-silenciamento.html Acesso em: 19/06/2019.

WOOLF, Virgínia. Um teto todo seu. São Paulo: Círculo do Livro S.A., 1928. 